\title{
PERCEPÇÕES HERMENÊUTICAS E VISUAIS \\ SOBRE A MODERNIDADE
}

André Krusser Dalmazzo

Resumo: A pretensão deste ensaio, de modo bem experimental, foi provocar a produção de imaginários sobre os conhecimentos humanos da modernidade e seus paradigmas, a partir das inter-relações das linguagens verbal e visual, mais especificamente, por meio de um exercício de leitura de imagens e textos que se complementam, e que tem a pretensão de gerar atmosferas contagiantes às percepções particulares das narrativas, pelo acréscimo da dimensão do sensível.

Palavras-chave: Sensibilidade. Linguagem visual. Imaginário. 


\begin{abstract}
The objective of the present essay, on an experimental level, was to engender the production of images regarding human knowledge of modernity and its paradigms from the starting point of interrelations between verbal and visual languages, more specifically, through an exercise of reading of images and texts that complement each other, with the intention of generating an atmosphere that reverberates to particular perceptions of narratives due to an emotional dimension.
\end{abstract}

Keywords: Sensibility. Visual language. Imaginary. 


\section{Introdução}

Tenho me questionado sobre a de produção e transmissão de conhecimentos a partir da percepção sensível de contextos estéticos e subjetivos, mais especificamente, com as possibilidades do redimensionamento dos discursos por meio da linguagem visual e a viabilidade para expressar pesquisas acadêmicas. Para tanto, realizei a experiência de produzir uma série de pinturas, interpretando muitas das ideias contidas nas leituras e debates de que participei ultimamente, e que me serviram como referências. Contudo, devo acrescentar que, em alguns momentos, processos inversos ocorreram, quando criei, primeiramente, imagens e só posteriormente surgiram textos que viriam interpretá-las.

A meu ver, isso se tornou possível porque senti que as construções se davam na medida em que eu imergia a estados criativos que de alguma maneira, subconsciente ou intuitiva, me faziam perceber a relação do meu entorno com o que eu desejava criar.

Entendo este processo como algo simples que ocorreu naturalmente em fases de leitura, interpretação, imaginação, intuição, escrita e pintura, mas sem uma ordem preestabelecida.

Outro aspecto que gostaria de chamar atenção é a relação que muitas vezes fazemos a respeito do tempo que dedicamos à leitura das imagens. Procurando compreendê-las instantaneamente, lemos as imagens em questão de segundos e, assim, ficamos sem a oportunidade de interpretá-las com profundidade. Por conta disso, gostaria de provocar uma reflexão, questionando se a compreensão de uma imagem requer tempo semelhante ao tempo que dedicamos à leitura de um conteúdo escrito.

Imagino que a resposta é particular, de cada indivíduo, tendo em vista a subjetividade e as simbolizações que as imagens carre- 
gam, e sendo a interpretação algo muito livre e pessoal em face da cultura, das experiências e do modo que cada um é educado para ler as linguagens visuais.

A seguir apresento uma série de enunciados, imagens e comentários com o objetivo de provocar olhares ou interpretações racionais e sensoriais sobre a temática dos conhecimentos humanos na modernidade e seus paradigmas.

\section{O ciclope atormentado}

Quando o filosofo árabe Avicena (980-1037) propôs que a alma era distinta do corpo, entrou em conflito com a ortodoxia islâmica. Mas seus pensamentos atravessaram a Idade Média e afloraram, em 1640, com as ideias de René Descartes e seu modelo dualista "mente e corpo", "verdadeiro e falso", "sim e não", "positivo e negativo", e assim por diante.

Embora o cartesianismo tenha sido refutado por outros pensadores no decorrer da história, ainda hoje percebemos oposições dualistas em discussões que envolvem a razão e a emoção, o racional e o sensorial, o científico e o religioso, ou mítico, o natural e o sobrenatural, o verbal e o visual, o real e o irreal e tantos outros antagonismos. Desta forma, Descartes apresentou as bases para a ascensão da ciência materialista no decorrer da modernidade. A comprovação disso fica evidenciada algum tempo depois da época deste filósofo e matemático, quando se instaura com toda a força a doutrina do positivismo de Augusto Comte, em que um dos preceitos basilares é: “[...] toda atividade do pensamento ou filosófica e a atividade artesanal e científica se exercem unicamente no âmbito da experiência do próprio homem e não por interven- 
ção de alguma divindade." (COMTE, 2000, p. 9).

Talvez nos seja mais fácil, hoje, pensar se quando tomamos como verdade apenas um ponto de vista ou nos voltamos somente a um dos ângulos de uma questão, não estamos assumindo certa cegueira a outros olhares, tal como o ciclope com sua visão periférica e limitada.

\section{O senhor da alma e o servo da matéria}

A presença do espírito positivo na construção da modernidade moldou a educação e as ciências, instaurando a supremacia do conhecimento científico sobre os demais saberes humanos.

Comte (2000, p. 23) considerava “[...] o estado metafísico como uma espécie de doença crônica naturalmente inerente a nossa evolução mental, individual ou coletiva, entre a infância e a virilidade."

Contrário a essa filosofia, Jean-Paul Sartre intentou que as ideias não têm outra existência senão a de objetos internos do pensamento, mas, para ele, elas nem sempre são conscientes. Sartre (2010, p. 18) diz que: "A existência da consciência desaparece totalmente por trás de um mundo de objetos opacos, que emitem, não se sabe de onde, uma espécie de florescência, aliás, caprichosamente distribuída, e que não desempenham nenhum papel ativo."

Sobre isso, entendo que quando nos prendemos a ideia de que o real e o verdadeiro são coisas objetivas, comprovadas a partir de métodos cartesianos ou positivistas, muito provavelmente, poderemos tornar-nos escravos de um mundo material, e sentiremos o peso dos objetos que nos impedem de perceber as fluorescências da alma e a liberdade de imaginar e transcender. 


\section{O dualista e o acaso}

Como uma carta alta, o pensamento fenomenológico parece imperar sobre o jogo da razão, sem se dar conta da sorte que o levou àquele lugar. Mas as percepções dos fatos da vida não podem ser compreendidas simplesmente por análises binárias dos fenômenos, com o que incorremos no risco de cair num dualismo maquinal, em que sobra pouco espaço à negociação e à flexibilidade necessárias às percepções das ocorrências fortuitas dos acasos ou das riquezas do imprevisível.

\section{A renúncia ao mundo das essências}

Por algum motivo - seguramente ilusório -, certos do conforto de termos a objetividade como o caminho mais seguro de acesso a verdades, e de podermos confiar que a aplicação de um método nos garantirá sempre o melhor traçado de uma trajetória, e nos logrará êxito na previsão do futuro, tendemos a desmerecer e desprezar nossos sentimentos e emoções, simplesmente, porque esses sentidos não são quantificáveis ou previsíveis.

Quando nos cegamos aos eventos alheios à objetividade do processo que estamos vivenciando, corremos o risco de encontrar conclusões antes mesmo de formularmos as questões que serão realmente pertinentes e que, provavelmente, irão gerar novas e instigantes questões que colocarão nossos pensamentos em movimento. Garnica (1997, p. 121) comenta que pesquisar é um exercício para compreendermos o mundo. Mas como investigar o mundo deixando de lado nossos sentimentos? 
Ao fecharmos o coração só resta seguirmos em direção ao óbvio ou ficarmos inertes em aparente monotonia.

Neste sentido, remetemo-nos à célebre frase de John Locke (apud SARTRE, 2010, p. 20), em seu Ensaio sobre o entendimento humano: "Nada existe no intelecto que não tenha passado pelos sentidos."

\section{O processador dialético}

É razoável que se diga que nem sempre podemos atuar de modo objetivo na reflexão de muitas das questões que nos surgem; isto porque os múltiplos aspectos e situações ligados à vida não dependem exclusivamente de nós: eles estão consignados à nossa interação com as outras pessoas e o mundo; estão atrelados ao diálogo e à nossa capacidade de nos colocarmos no lugar do outro, compreendendo e formulando diferentes pontos de vista sobre o mesmo assunto ou acontecimento. Assim, passamos a pensar sob outros ângulos, contando com a nossa capacidade de processar e multiplicar o caráter diverso das ideias.

A difusão da abordagem dialética, principalmente pelo filósofo alemão Georg Wilhelm Friedrich Hegel (1770-1831), abriu espaço para a compreensão, na modernidade, das estruturas de pensamento e consciência como algo mutável, considerando que toda realidade é um processo histórico. E sendo históricos, os fenômenos demandam oposições para obter resoluções. Como propunha Hegel, a dialética é o que torna possível o aperfeiçoamento da realização da realidade (MORA, 2000, p. 721), porquanto é justamente pela sua negação que ela se torna positiva. $\mathrm{O}$ "processador 
dialético" busca a síntese entre a realidade e a razão, mas mais do que isso, ele precisa do movimento do pensamento que realiza a realidade.

\section{Hermes, o interpretador}

Percebemos, assim, que a oposição e qualificação das ideias promovem novos pensamentos, novas realidades, mas a construção de conhecimentos deve se efetivar a partir de interpretações aprofundadas, sustentadas pela história e suas circunstâncias, pela capacidade dos indivíduos avaliarem e decidirem sobre os temas seja no âmbito macro ou micro - que mais diretamente invadem suas vidas.

Como afirma Jürgen Habermas (2009, p. 198), “a experiência hermenêutica traz à consciência a posição do sujeito falante em relação à linguagem" e ao mundo.

Assim, ao encarnarmos Hermes, com um olhar aguçado sobre o mundo e as experiências, imergimos em simbolizações e linguagens que nos permitem movimentar imaginários e compreender a nós e o mundo em que vivemos; ou seja, compreender que realidade está sendo realizada.

\section{Sujeito moderno, crítico-neurótico}

Esses e outros olhares sobre o mundo e a vida nos constituíram, por um lado, como seres críticos, kantianos, questionadores e idealistas, conscientes do desenvolvimento da humanidade e, consequentemente, empenhados em compreendê-la para ir além, 
realizando transformações em seu contexto histórico. Por outro lado, tornamo-nos sujeitos neuróticos, freudianos, herdeiros da tradição cristã ocidental, tementes e devedores a grandes sujeitos, ao pecado e a culpa.

E, assim, avançamos até o limiar da modernidade como seres "xifópagos"; presos a um só corpo; negociantes de vontades críticas e neuróticas e despertados por uma melancolia frente à obscuridade dos paradigmas pós-contemporâneos e à imperfeição do mundo.

\section{O paradigma da modernidade}

Ultrapassamos a modernidade? As utopias se extinguiram? Libertamo-nos dos grandes sujeitos? Somos reais ou simbólicos? Estas e outras indagações nos instigam a pensar no que nos tornamos e o que seremos amanhã.

\section{Sujeito/objeto pós-contemporâneo}

É senso comum que em poucos anos tivemos massivas implementações tecnológicas que fizeram aumentar ainda mais o poderio econômico e os interesses mercadológicos, seduzindo-nos pela oferta desenfreada de serviços e objetos cada vez mais técnicos e complexos, que, segundo a ótica neoliberal, servem para suprir qualquer de nossas necessidades, inclusive a felicidade.

A ideia originária de uma ferramenta era que servisse para facilitar o trabalho humano, mas as máquinas atuais vão muito além deste propósito: servem à mecanização total de nossas vidas. Vemos que quase tudo o que consumimos passa por processos industriais, 
num grau técnico de transformação jamais pensado. E na prateleira, de modo quase singelo, o produto pronto, embalado, à nossa mão.

Consequência disso mesmo é o fato de que as tecnologias, por intermédio dos avanços dos sistemas de comunicação, promoveram a desmaterialização dos nossos relacionamentos, dispensando-nos da presença física, instituindo-nos como sujeitos virtuais. Ou seja, sujeitos/objetos dos quais podemos prescindir em favor de um novo, que seja mais conveniente segundo as tendências do mercado das aparências.

\section{A roda do consumo}

Também é senso comum que as "seduções" empacotadas, oferecidas no mercado, têm quase o mesmo tempo de vida útil que decorre de um ímpeto a outro para se voltar a comprar, o que nos torna vassalos do sistema de produção-consumo-descarte. E se em algum momento desse processo não dermos conta desse movimento, então nós é que poderemos ser descartados.

A este respeito, Dany-Robert Dufour comenta que:

O sujeito, tendo buscado no objeto a satisfação de seu desejo, pode apenas descobrir, sendo dada a natureza da pulsão, que 'ainda não era isso', que a falta que havia suscitado o desejo persiste. Ora, essa decepção consecutiva ao recebimento de cada objeto é a melhor aliada da extensão ampliada da mercadoria na medida em que ela só pode relançar o ciclo da demanda do objeto. (DUFOUR, 2005, p. 77).

Como Boécio (ca. 480-524 ou 525), na antiguidade, utilizou-se da imagem da roda para demonstrar o sentido de movimento da fortuna e a crueldade e como ela trata os homens, eu busquei ins- 
piração na iluminura L'Hortus Deliciarum, de Herrade de Landsberg, para ilustrar a sorte dos homens no movimento de consumo imposto pelo mercado nos dias de hoje.

\section{O auto-olhar e o peso insustentável do egocentrismo}

Dufour (2005, p. 25) conjectura que o sujeito que se apresenta nos dias de hoje não é mais globalmente o mesmo que se apresentava a uma década.

O contexto tecnológico, globalizado e neoliberal, imposto pelo poder mercadológico mundial, extingue alguns valores da modernidade em favor de outros, como a valorização da aparência e da embalagem; a superficialidade na contrapartida da velocidade dos acontecimentos; o individualismo promovido pela autossuficiência do consumo, e a destituição do referencial dos grandes sujeitos em favor de um egocentrismo desconfortavelmente patológico. Tudo isto na medida em que nos tornarmos grandes sujeitos de nós mesmos. Essa é uma situação nova e problemática da nossa contemporaneidade. Para Dufour (2005, p. 26): “[...] a ausência de enunciador coletivo que tenha crédito, cria dificuldades inéditas para o acesso à condição subjetiva e pesa sobre todos, e particularmente sobre os jovens."

\section{Divindade hi-tech}

Vivemos uma época de deslumbramento tecnológico? Mas que outros olhares se pode ter deste panorama? Tornamo-nos deuses tecnologizados de nós mesmos? 
A banalização dos sujeitos na pós-modernidade está presente no discurso de Dufour, quando ele diz:

[...] é no espaço vacante deixado por essa queda atual dos ideais do eu e do supereu em sua face simbólica que se entranha o mercado. Os publicitários já entenderam que partido poderiam tirar dessa derrocada do supereu para tentar instalar as marcas como novas referências. O mercado (notadamente o mercado da imagem) assim se tornou um grande provedor desses novos ideais do eu voláteis, em constante remanejamento. (DUFOUR. 2005, p. 107).

Levamos nossas vidas sobre modo reguladas e normatizadas, urgentes de respostas rápidas, que se torna, praticamente, inviável pensar em algo verdadeiramente autêntico. Mesmo os processos mais qualitativos são quantificados sob o jugo de um produtivismo desenfreado.

Não obstante, prefiro pensar que como seres sensíveis e sociais que somos, e providos de sentimentos e valores nobres, necessitamos construir um sentido maior a nossas existências que não a mera acumulação das riquezas materiais. Porque é possível construir algo original à medida que nos afastamos dos dogmas e percebemos que outras linguagens podem articular a produção de novos imaginários, produzindo novos saberes sobre a arte de viver e pensar.

Por fim, espero que as imagens sejam muito mais representativas que os modestos enunciados que as acompanham, e que despertem os sentimentos mais simples e sublimes que só a arte é capaz de expressar. 


\section{Referências}

COMTE, A. Discurso sobre o Espírito Positivo. São Paulo: Escala, 2000.

DESCARTES, R. Discurso sobre o método. 9. ed. Curitiba: Hemus, 2000. Disponível em <http://www.4shared.com/office/heTMF06hDescartes Discurso do metodo.html>. Acesso em: 4 set. 2012.

DUFOUR, D-R. A arte de reduzir cabeças: sobre a nova servidão na sociedade ultraliberal. Rio de Janeiro: Companhia de Freud, 2005.

ESCOBAR, A. O lugar da natureza e a natureza do lugar. In. LANDER, E. A colonialidade do saber: Eurocentrismo e ciências sócias - perspectivas latino-americanas. Bueno Aires: Clacso, 2005.

GADAMER, H. G. Sobre a originalidade da ciência. In: Hermenêutica em retrospectiva. São Paulo: Vozes, 2009.

GARNICA, A. V. M. Algumas notas sobre pesquisa qualitativa e fenomenologia. Interface - Comunicação, Saúde, Educação, v. 1, n. 1, 1997. Disponível em <http://www.scielo.br/pdf/icse/v1n1/08.pdf>. Acesso em: 17 fev. 2012.

HABERMAS, J. A pretensão de universalidade da Hermenêutica. In: A lógica das ciências sociais. Rio de Janeiro: Vozes, 2009.

HEGEL, G. W. F. Fenomenologia do Espírito. Parte I. 5. ed. Rio de Janeiro: Vozes, 2008.

HEIDEGGER, M. Meu caminho para fenomenologia. São Paulo: Abril Cultural, 1973. Disponível em <http://www.ensinarfilosofia.com.br/ pdfs/elivros/26.pdf>. Acesso em: 17 fev. 2012.

JAPIASSU, H. O Problema da história das ciências; o problema da objetividade; o estudo epistemológico das ciências humanas. In:

(Org.). Questões epistemológicas. Rio de Janeiro: Imago, 1981. p. 45126.

LUNA, S. V. de. O falso conflito entre tendências metodológicas. Cadernos de Pesquisa, n. 66, p. 70-74, 1988. Disponível em: <http:// 
educa.fcc.org.br/pdf/cp/n66a07.pdf>. Acesso em: 17 fev. 2012.

MACEDO, D. O multiculturalismo para além do jugo do positivismo. Currículo sem fronteiras, v. 4, n. 1, p. 101-114, jan./jun. 2004. Disponível em: <http://www.curriculosemfronteiras.org/vol4iss1articles/macedo. pdf $>$. Acesso em: 17 fev. 2012.

MORA, José Ferrater. Dicionário de Filosofia. São Paulo: Loyola, 2000.

PINTO, A. Ciências e Existência: problemas filosóficos da pesquisa cientificam. Rio de Janeiro: Paz e Terra, 1985. p. 173-196.

POPPER, K. O Status da ciência metafísica. In: (Org.). Conjecturas e Refutações. 5. ed. Brasília: Ed. UNB, 2008. p. 211-226.

SANTOS, B. S. Do pós-moderno ao pós-colonial e para além de um e outro. In: (Org.). A gramática do tempo: para uma nova cultura política. 2. ed. São Paulo: Cortez, 2008. p. 25-47.

SARTRE, J. P. Os grandes sistemas metafísicos. In: A imaginação. Porto Alegre: L\&PM, 2010.

SOARES, L. E. Hermenêutica e ciências humanas. Estudos Históricos, Rio de Janeiro, n. 1, 1988. Disponível em: <www.bibliotecadigital.fgv. br/ojs/índex.php/reh/article/download/1932/1071>. Acesso em: $17 \mathrm{fev}$. 2012.

\section{Referência visual}

LANDSBERG, Herrade de. L'Hortus Deliciarum. 1165. Disponível em: $<$ http://www.ricardocosta.com/artigo/boecio-e-ramon-llull-roda-dafortuna-principio-e-fim-dos-homens $>$. 


\section{Notas}

Em meio a esse processo que acabei de descrever, pensei em algumas qualidades que achei curioso explicitar:

${ }^{1}$ Adotei um estilo de pintura que lembram os grafitis e cartuns, que são marcas visuais de nossa contemporaneidade ou da dita pós-modernidade.

${ }^{2}$ Nas pinturas, reduzi a significância verbal das palavras para utilizá-las como elementos estéticos em outra dimensão expressiva que não a verbal.

${ }^{3}$ As representações das figuras humanas são sintéticas e deformadas, talvez banalizadas em suas formas, servindo como um olhar sobre a incompletude do ser humano e sua ingenuidade frente à complexidade da vida pós-moderna. ${ }^{4} \mathrm{O}$ caráter fantástico das imagens foi pensado como potencial à construção de pensamentos imaginários livres. Pois, como disse Hebert Marcuse (1941): "Aquilo que é não pode ser verdade." 
